\title{
Faults effects analysis in a photovoltaic array based on current-voltage and power-voltage characteristics
}

\author{
Siwar Fadhel ${ }^{(1)(2)(3)}$, Mohamed Trabelsi ${ }^{(1)}$, Imen Bahri ${ }^{(3)}$, Demba Diallo ${ }^{(3)}$, Mohamed Faouzi Mimouni ${ }^{(1)}$ \\ ${ }^{(1)}$ Research Unit of Industrial Systems and Renewable Energy (ESIER), National Engineering School of Monastir, University of \\ Monastir, Tunisia \\ ${ }^{(2)}$ National Engineering School of Sousse, University of Sousse, Tunisia \\ ${ }^{(3)}$ Group of Electrical Engineering, Paris (GeePs), CNRS UMR 8507; Centrale Supelec; Univ. of Pierre and Marie Curie P6; \\ University of Paris-Sud; University of Paris Saclay, France \\ E-mails : \{ siwar_fadhel@yahoo.fr, medtrabelsii@yahoo.fr, imen.bahri@geeps.centralesupelec.fr; \\ demba.diallo@geeps.centralesupelec.fr,mfaouzi.mimouni@enim.rnu.tn\}
}

\begin{abstract}
This paper deals with studying the behavior of a photovoltaic (PV) array in faulty conditions. In this context, the authors propose a new approach offering a good evaluation of the PV array performances under progressive faults. The approach implemented in Matlab/Simulink, is based on the analysis of anomalies shown in current-voltage (I-V) and powervoltage $(\mathrm{P}-\mathrm{V})$ characteristics, which are obtained when the $\mathrm{PV}$ array is subjected to progressive faults at its basic components (PV cell, bypass diodes, blocking diodes), at its PV modules and at connectivity between the PV modules. The proposed method would be used to deduce diagnostic information about the state of health of the PV array.
\end{abstract}

Keywords_photovoltaic array; faults modeling; progressive faults ; faults signatures

\section{INTRODUCTION}

As the amount of PV energy mainly depends on the environmental conditions and failures in PV generators, the last decades have been witnessed a great deal of research effort devoted to maximizing the output power of the PV generators. Their diagnosis is very important as it can provide users with a warning of the system failure risks. The electrical faults are the main source of failures in a PV generator. The short circuit [23], open circuit [3], impedance [4], reversed polarity [4-5] and partial shading faults [6-7] are the major faults known in the field of the PV diagnosis [8]. These faults can occur at the basic components, at the PV modules and at the PV strings. The electrical behavior of a photovoltaic generator can be described by its I-V and P-V characteristics. Therefore, observing these characteristics is very interesting as it provides with information about the state of health of the PV generator from current, voltage and power data. Compared to the prior-art approach [9]-[10], of using the I-V and P-V curves for diagnosis, the proposed approach utilizes a different PV and faults modeling technique. In these works, the approach used for modeling the PV array is based on known electrical laws as voltages and currents addition in series and in parallel, and on nodes law. However, the approach used in this paper, is based on connecting solar cells to build the PV modules and the PV strings. These strings are connected in parallel to from the final
PV array. The electrical faults are represented by the I-V mathematical equations in the cited studies. However, in this paper, the Matlab/Simulink software is used to represent these faults physically. In this work, the authors propose to study the faulty behavior of a PV array when it is subjected to progressive faults as increasing the number of faulty components and increasing the faults amplitude. The case when all the strings are faulty simultaneously is also simulated. This methodology allows quantifying the effect of these faults at their different degrees.

This paper is organized as follows. Section II presents the PV array structure and the PV mathematical model. Section III presents a brief description of the typical faults in a PV array, and simulation results of five electrical faults (bypass diode faults, blocking diode faults, PV cell faults, faults in the modules and connectivity faults). Conclusion ends this paper.

\section{MODELING APPROACH IN HEALTHY CONDITION}

\section{A. PV structure}

Since an individual PV cell produces approximately only $0.5 \mathrm{~V}$, a PV module, which is the basic block for PV systems, is used from connecting several PV cells in series to deliver higher voltage. A typical module has 36 cells in series. 72-, 96and 128-cells module are now quite common and used [11]. Multiple modules, in turn, can be connected in series to increase the voltage and in parallel to increase the current and form the PV strings. Such combination is referred to as an array. The PV array can be built in series-parallel (SP), in total cross-tied (TCT), and in bridge-Link (BL) topology [12]. In practice, the SP topology is often used because it requires fewer connections [12]. Figure 1 illustrates the studied PV array built in a SP configuration. It consists of three parallel PV strings. A blocking diode is mounted on the top of each string to block the reversed current in some faulty conditions. Each string is formed with two series-connected modules, where each one contains four groups of eighteen cells. Finally, each group is protected by an antiparallel-connected bypass diode. 


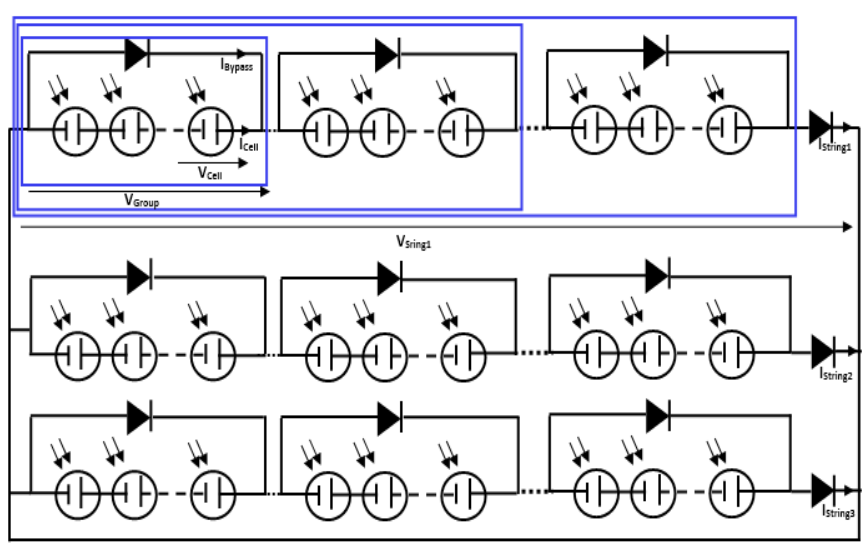

Figure 1: Studied photocoltaic array

\section{B. PV model}

The common models used to reproduce the I-V and P-V characteristics that define the electrical behavior of a PV cell in normal and faulty conditions, are based on one diode and two diodes equivalent electrical circuit. Recently, other models have been developed to offer a better modelisation of the physical phenomena of the charge carries in a PV cell. Reference [1] presents the most electrical models available in the literature with more details.

The complete PV array model is achieved by using the single diode PV cell model shown in fig. 2 and described by the I-V equation (1):

$I_{\text {cell }}=I_{P H}-I_{O}\left[\exp \left\{\frac{\left(V_{\text {cell }}+I_{\text {cell }} * R_{S}\right)}{V_{t}}\right\}-1\right]-I_{\text {sh }}$

Where:

$I_{P H}=\left[I_{S C r}+K_{i}\left(T-T_{r e f}\right)\right] * \frac{G}{G_{\text {ref }}}$

$V_{t}=\frac{n \cdot K \cdot T}{q}$

$I_{s h}=\frac{\mathrm{v}_{c e l l}+R_{S} * I_{\text {cell }}}{R_{S h}}$

Where $T_{\text {ref }}\left(298^{\circ} \mathrm{k}\right)$ and $T$ are the temperature at reference and real conditions respectively; $G_{\text {ref }}\left(1000 \mathrm{w} / \mathrm{m}^{2}\right)$ and $G$ are the irradiation at reference and real condition respectively; $I_{O}$ is the saturation current of the diode; $I_{s c r}$ is the short circuit current at reference condition ; $n$ is the ideality factor of the diode ; $k$ is the Boltzmann constant $\left(1.38 .10^{23} \mathrm{~J}^{-\mathrm{K}^{-1}}\right) ; q$ is the electron charge $\left(1.602 .10^{-19} \mathrm{C}\right) ; K_{i}$ is the temperature coefficient of the short circuit current $\left(\mathrm{A} /{ }^{\circ} \mathrm{C}\right) ; R_{s}$ and $R_{s h}$ are the series and shunt resistance respectively $(\Omega)$.

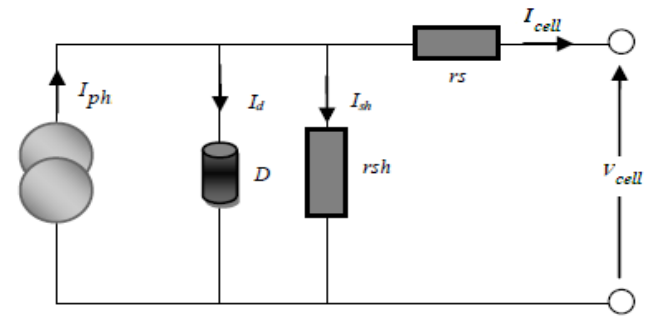

Figure 2: One diode electrical model

Figure 3 illustrates the I-V and P-V characteristics of the $\mathrm{PV}$ array at reference condition.

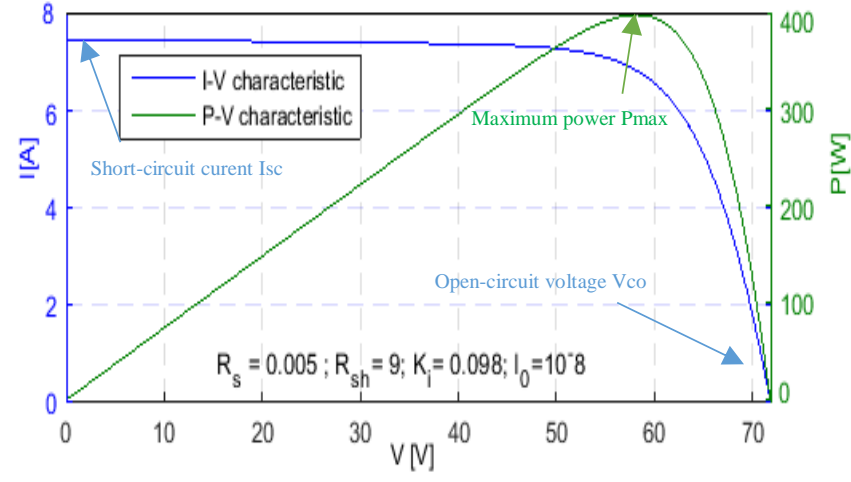

Figure 3: Healthy I-V and $P$-V characteristics at reference condition

\section{MODELING APPROACH IN FAULTY CONDITIONS}

\section{A. Typical faults in a PV array}

In an ideal solar array, array power is simply the sum of individual module powers. Nevertheless, several conditions (environmental changes or/and hardware failures) result in available power from the array being significantly below predicted level. The main hardware faults usually occur in PV modules and electrical connections as shown in Fig.4. We examine the causes and effects of some of these faults before giving simulation results.

1) Connectivity faults: This fault may be formed within a string or a module during the manufacturing process, during array assembly if connections are not made tightly, or over time due to factors as thermal stresses. This fault become more serious when a high resistance connection occurs. Indeed, high resistance connection may eventually separate fully, leading to a series arc fault or open circuit. It increases the effective series resistance of a module, which lead to reduced power output.

2) DC arc fault: The DC arc fault is a spark across air or conductors dielectric and occurs in two forms: series and parallel. Series arcs can occur at the cable connections, in the junction boxes and within modules. Parallel arcs can occur when two conductors with different voltage are placed near each other. This fault can lead to inefficiency in array operation since it can disable the entire string in which it occurs, frequently cause failure of bypass diodes [14] and can even cause fires. Unlike other faults mentioned in this section, arc faults are a transient phenomenon and there are complex techniques needed to model this transient behavior.

3) Ground fault: It happens when the circuit develops an unintentional path to ground. In a PV system, it is usually caused by the damage in the protective insulation of normally current-carrying conductors. This results in lowered output voltage and power and can be fatal if the leakage currents are running through a person.

4) Line-line fault: A line-line fault is an accidental lowresistance connection established between two points of different potential among PV modules and array cables. It can be caused by insulation failure of cables and line-line faults 
within the junction box, caused by mechanical damage, water ingress or corrosion. This fault results in overcurrent in the faulty string and could be high enough to damage PV modules and conductors increasing the risk of fire hazard and weakening the overall efficiency of the PV system

5) Shading: Shading is also a serious concern in PV array. It is the partial or the total blockage of PV modules surface from the sunlight. It reduces the current generated by the shaded cells, which in turn reduces the maximum current produced by the other series connected cells. In order to mitigate the effects of shading, bypass diodes are used to prevent healthy cells form being into reverse bias that can generate damaging reverse breakdown voltage and hotspot zones. So, this fault can damage modules if not properly controlled.

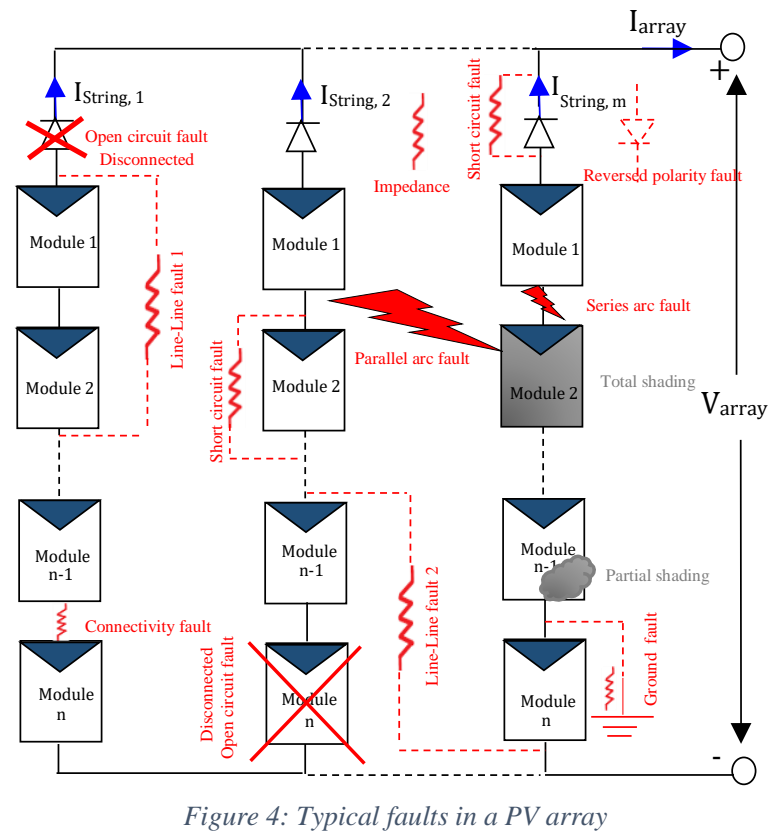

B. Simulation results

\section{1) Blocking diode faults}

a. Short circuit

This fault can be classified among the most danger faults than can occur in a PV array. As shown in fig.5 the faulty I$\mathrm{V}$ and $\mathrm{P}-\mathrm{V}$ characteristics are similar to the healthy ones. We note 0.6 volts increase in the open circuit voltage $\mathrm{V}_{\text {co }}$ for one faulty blocking diode. This is equal to the drop voltage introduced in the wire when connecting this diode.

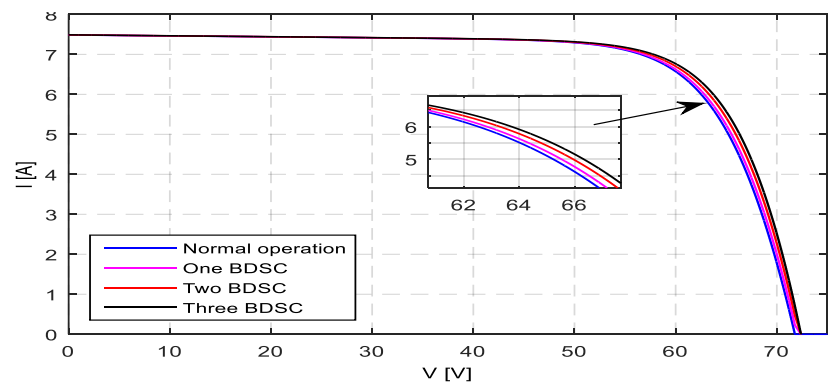

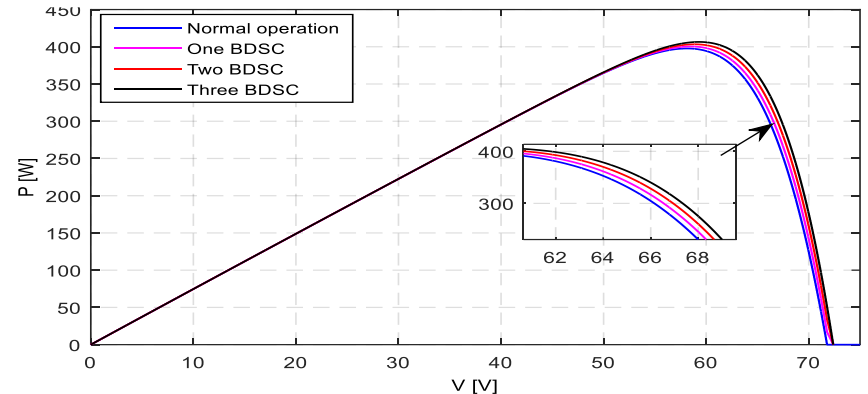

Figure 5: I-V and P-V curves under short-circuited blocking diodes

\section{b. Open circuit}

The results shown in fig. 6 demonstrate that the existence of an open circuit fault at the level of blocking diode causes a significant degradation in the produced power of the PV array. Indeed, one faulty blocking diode cancels the current flowing by the faulty string, then a decrease of $1 / 3$ total short circuit current $\mathrm{I}_{\mathrm{sc}}$ is observed, causing power degradation.
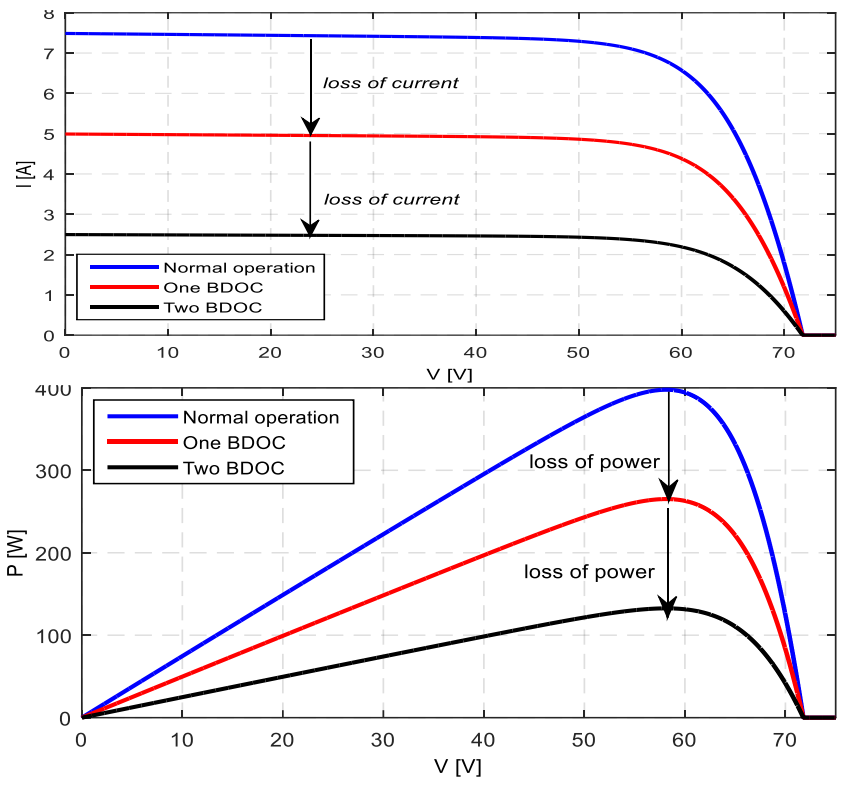

Figure 6: I-V and P-V curves under open-circuited blocking diodes

\section{c. Impedance}

When a blocking diode submits to the impedance fault, it permits the current flow in both directions and causes a significant degradation in the maximum produced power $\mathrm{P}_{\max }$. Figure7 shows that the slope of the I-V curve changes proportionally to the impedance value. We notice that this type of fault behaves as an open circuit fault for higher values of the impedance, as it reduces the $\mathrm{I}_{\mathrm{sc}}$ value.

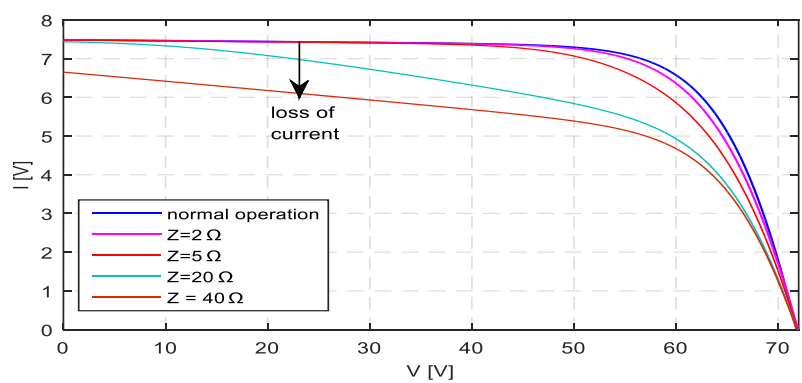




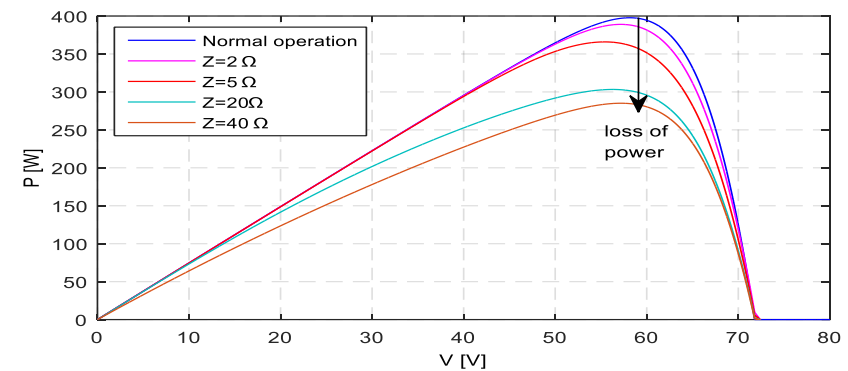

Figure 7: I-V and P-V curves under impedance blocking diodes

\section{d. Reverse polarity}

Figure 8 shows that the reversed polarity fault of a blocking diode have the same influence when this component is submitted to the open circuit fault.
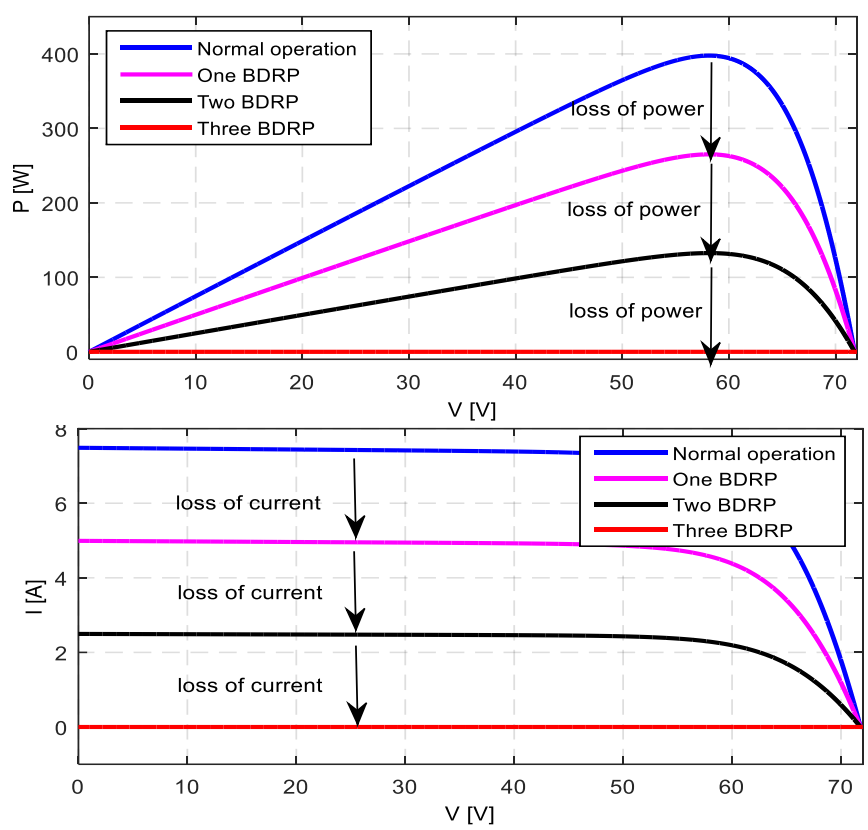

Figure 8: I-V and P-V curves under reversed-polarity blocking diodes

\section{2) Bypass diode faults}

Assuming that only the bypass diode is the faulty component, the open circuit fault has no impact on the I-V and $\mathrm{P}-\mathrm{V}$ curves. So, this fault is not considered in these simulations.

\section{a. Short circuit}

When all the strings are subjected simultaneously to the same fault (fig. 9(a)), the $\mathrm{V}_{\text {co }}$ value drops proportionally to the number of the faulty bypass diodes. Indeed, this fault cancels the voltage ( $9 \mathrm{~V}$ approximately) of the group, which is in parallel to the faulty diode. However, when these strings are not subjected to the same degree of fault, the I-V curve contains an inflection point that justify the action of the blocking diode (fig.9 (b)). This inflection appears at the open circuit voltage of the faulty string. Fig.9(c) presents a comparison between the impact of a frank short circuit and a progressive one. For this latter case, the faulty diode is shunted with a small resistance. The smaller the resistance value is, the more the voltage $\mathrm{V}_{\text {co }}$ is lost. This result is also observed for simultaneous fault in the strings. Figure 9(d) demonstrates that the inflection appears for a voltage smaller than the one appeared for a frank short circuit.
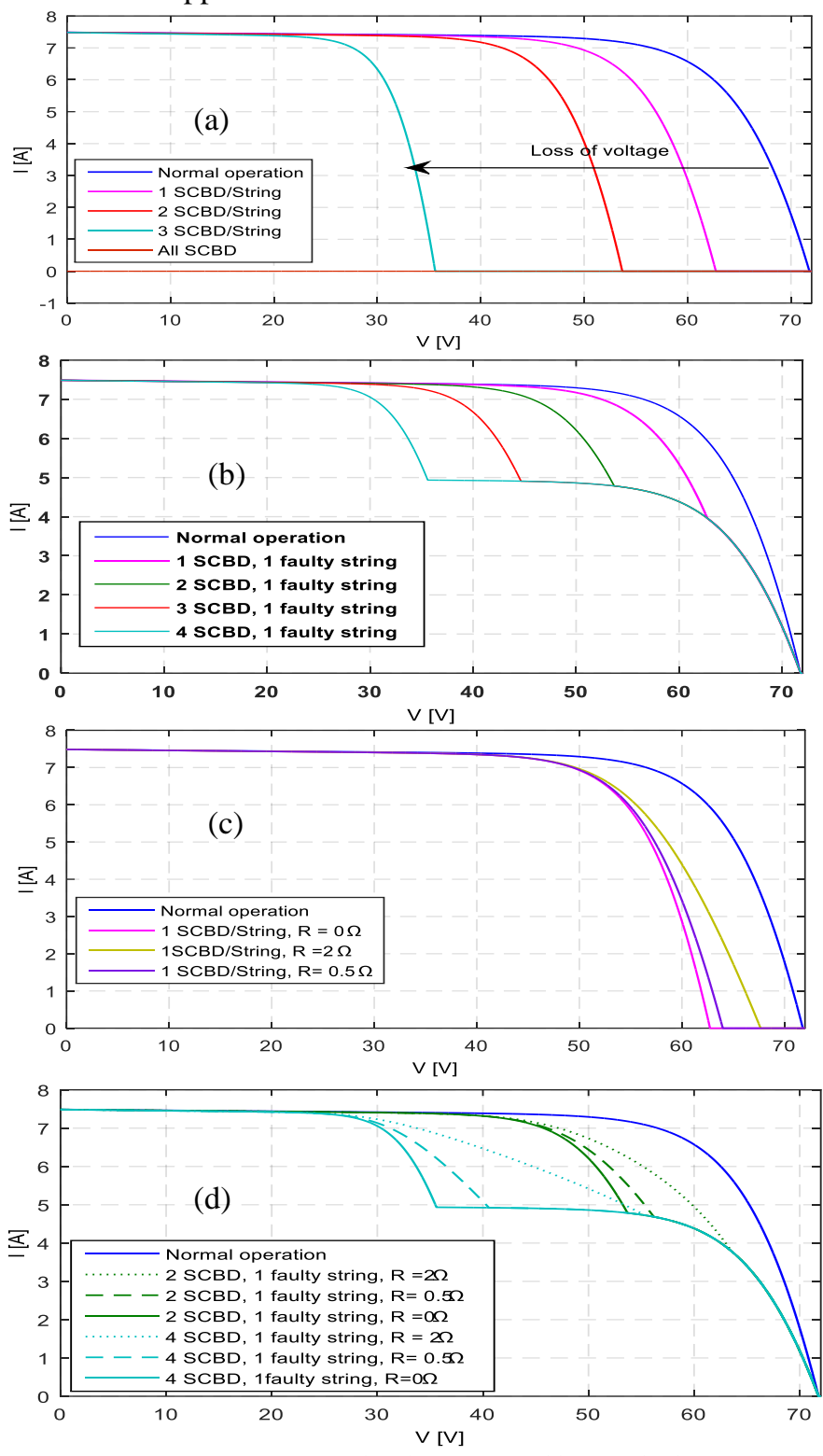

Figure 9: I-V curves under short-circuited bypass diodes

\section{b. Impedance}

In this scenario, the faulty bypass diode behaves as a resistance. As shown in fig.10, the I-V curve slope changes depending on the resistance value. We note that the short circuit fault have greater impact than this fault.

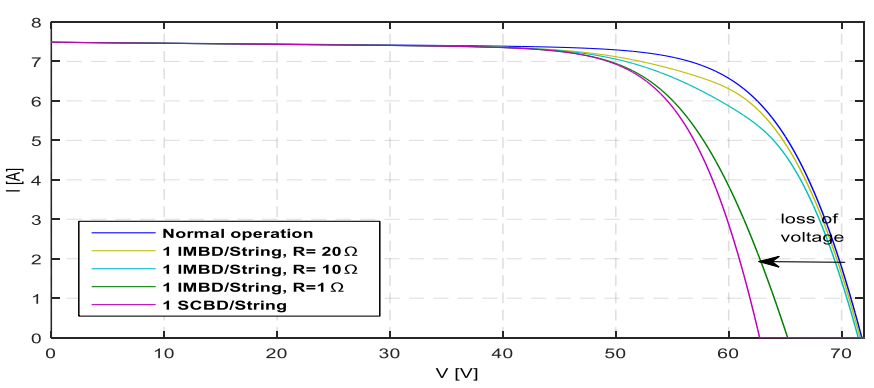

Figure 10: I-V curves under impedance bypass diode 


\section{3) PV cell faults}

\section{a. Short circuit}

Figure 11(a) shows the I-V curve when one string contains defective groups of cells. This fault has the same impact as defective bypass diode (see fig. 9(b)). Figure 11(b) shows that the open circuit voltage decreases proportional to the number of defective cells when all the strings are submitted to the same fault. Otherwise, the I-V curve contains a point of inflection that proves the action of the blocking diode mounted on the top of the faulty string.
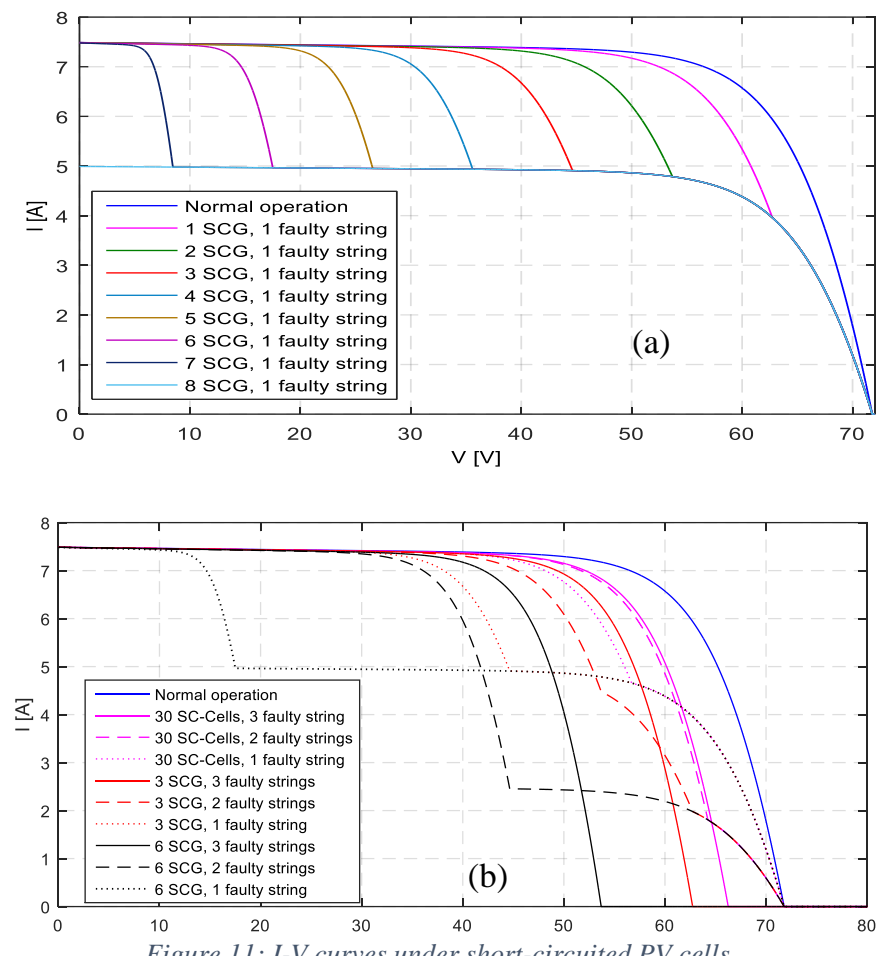

\section{b. Partial shading}

Figure 12 shows the I-V and P-V curves under nonuniform irradiation. In this simulation, two groups in the first string are $50 \%$ shaded and two groups in the second string are $25 \%$ shaded. Partial shading leads to decrease the current flow in the string when the shaded groups are not protected with bypass diodes (dashed curves). This decrease is transformed to inflection point (red curves) with presence of these diodes. In fact, these points indicate that the bypass diodes became active and pass the current around the affected groups.

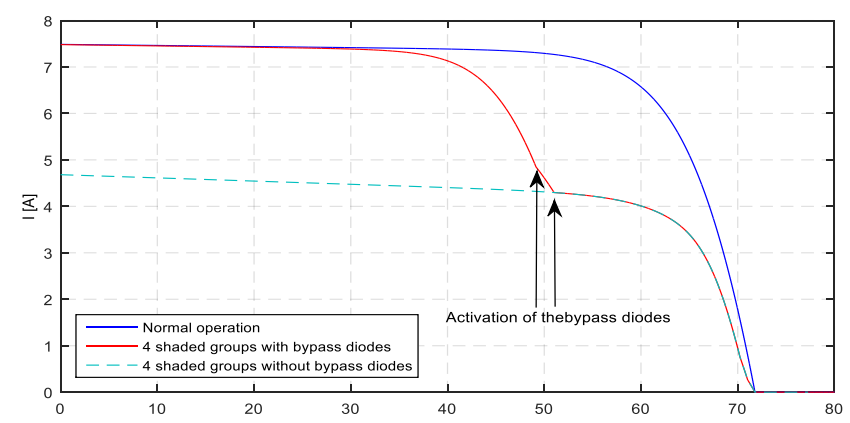

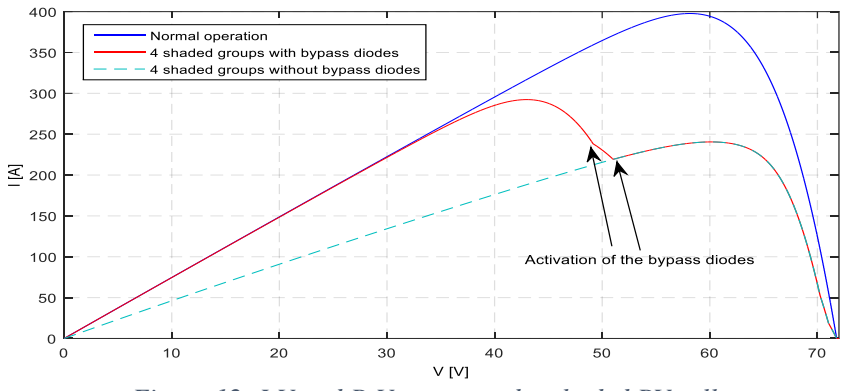

Figure 12: I-V and P-V curves under shaded PV cells

\section{4) Faults in the modules}

In this scenario, only the short circuit module fault is considered. Two cases are presented; a frank short circuit and progressive one. The smaller the shunt resistance value is, the more the open-circuit voltage is lost (fig.13). The I-V characteristic under frank short circuit contains a point of inflection that proves the action of the blocking diode. When the strings are submitted simultaneously to the same fault, a $50 \%$ drop in $\mathrm{V}_{\text {co }}$ value is observed.

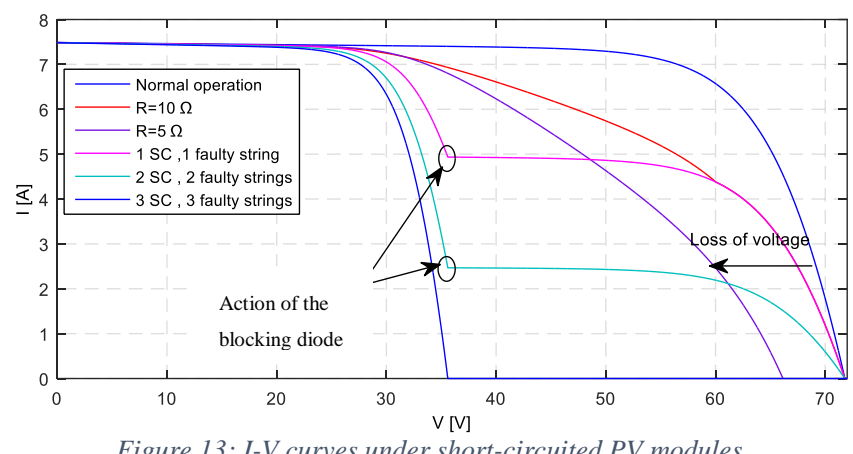

\section{5) Connectivity fault}

The reason of power degradation could also be the increase in the series resistance between PV modules. In this scenario, the connection between two modules is replaced by a resistance with different values as shown in fig.14. The I-V curve slope changes as a function of the resistance value.

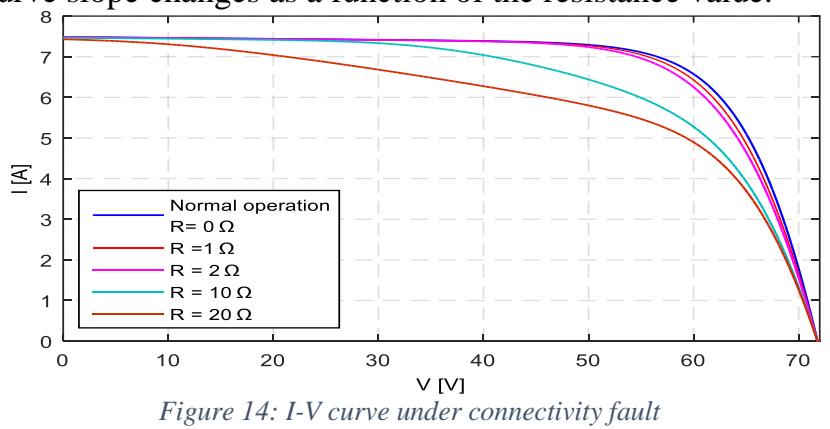

\section{Discussion}

The comparison of the I-V and P-V characteristics for a PV array under the faults as summarized in table1, with the ones under healthy operation leads to identify four anomalies: open circuit voltage $\left(\mathrm{V}_{\mathrm{co}}\right)$ drop, short circuit current $\left(\mathrm{I}_{\mathrm{sc}}\right)$ drop, slope deviation and inflection point in the characteristics. Figure 15 presents the flowchart of the faults analysis, where $n$ is the number of PV groups and $\alpha$ an integer. 


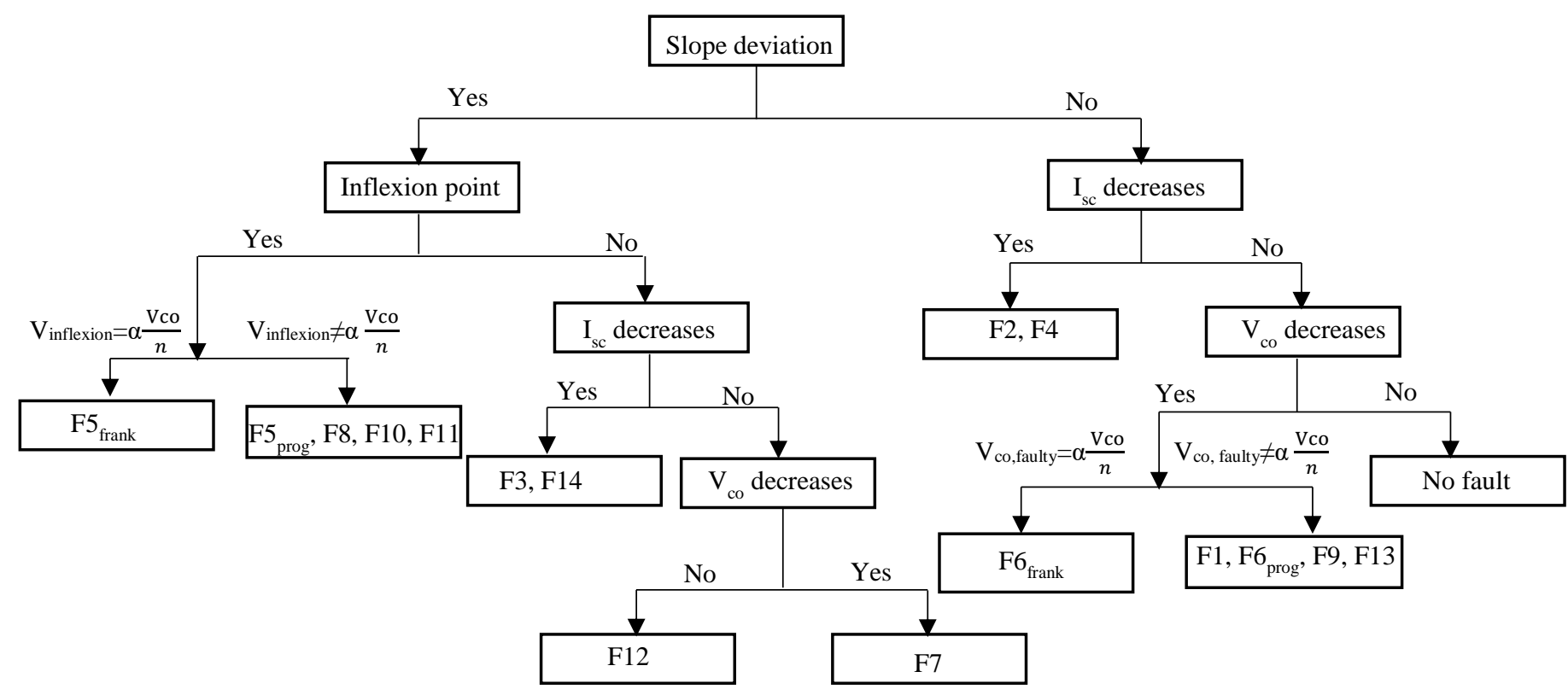

Figure 15: Proposed faults identification

Table 1: Different faults and their descriptions

\begin{tabular}{|c|c|c|}
\hline Types of faults & Description & Symbol \\
\hline \multirow{4}{*}{$\begin{array}{l}\text { Blocking } \\
\text { diode }\end{array}$} & Short circuit & $\mathrm{F} 1$ \\
\hline & Open circuit & $\mathrm{F} 2$ \\
\hline & Impedance & F3 \\
\hline & Reverse polarity & $\mathrm{F} 4$ \\
\hline \multirow{5}{*}{ Bypass diode } & Frank short circuit in any string & $\mathrm{F} 5_{\text {frank }}$ \\
\hline & Progressive short circuit in any string & $\mathrm{F} 5_{\text {prog }}$ \\
\hline & $\begin{array}{l}\text { Homogenous frank short circuit in the } \\
\text { strings }\end{array}$ & $\mathrm{F} 6_{\text {frank }}$ \\
\hline & $\begin{array}{l}\text { Homogenous progressive short circuit in the } \\
\text { strings }\end{array}$ & $\mathrm{F} 6_{\text {prog }}$ \\
\hline & Impedance & F7 \\
\hline \multirow{3}{*}{ PV cells } & Short circuit in any string & F8 \\
\hline & Homogenous short circuit in the strings & F9 \\
\hline & Partial shading & F10 \\
\hline \multirow{3}{*}{ PV modules } & Frank short circuit in any string & F11 \\
\hline & Progressive short circuit in any string & F12 \\
\hline & Homogenous short circuit in the strings & F13 \\
\hline Connectivity & Two modules connected by a resistance & F14 \\
\hline
\end{tabular}

\section{CONCLUSION}

This paper presented a fault analysis technique for a photovoltaic array based on its I-V and P-V characteristics. The solar cell element available in the library of Matlab/Simscape was used to build the studied array. With reference to the faults classification, fault detection and identification algorithm will be developed. The effect on the maximum power tracking will be the subject of further works.

\section{REFERENCES}

[1] Alain K. Tossa, Y.M. Soro, Y. Azoumah, D. Yamegueu " A new approach to estimate the performance and energy productivity of photovoltaic modules in real operating conditions", Solar energy, vol. 110, pp. 543-560, December 2014.

[2] Wail Rezgui, Nadia Kinza Mouss, Leïla-Hayet Mouss,Mohamed Djamel Mouss, Yassine Amirat and Mohamed Benbouzid, "Modeling the PV Generator Behavior Submit to the Open-Circuit and the Short-Circuit Faults", Environmental Friendly Energies and Applications (EFEA), 2014 3rd International Symposium on, pp.1-6, 19-21 Nov. 2014.

[3] S. Hadji, J.-P. Gaubert, F. Krim, "Maximum Power Point Tracking (MPPT) for Photovoltaic systems using open circuit voltage and short circuit current ', in Proceedings of the 2013

[4] Wail Rezgui, Nadia Kinza Mouss, Leïla-Hayet Mouss,Mohamed Djamel Mouss, Yassine Amirat and Mohamed Benbouzid,"Faults Modeling of the Impedance and Reversed Polarity Types within the PV Generator Operation", Environmental Friendly Energies and Applications (EFEA), 2014 3rd International Symposium on, pp.1-6, 19-21 Nov. 2014.

[5] W. Rezgui, L.H. Mouss, N.K. Mouss, M.D. Mouss and M.E.H Benbouzid, " A Regression Algorithm for the Smart Prognosis of a Reversed Polarity Fault in a Photovoltaic Generator", in Proceedings of the 2014 IEEE ICGE, Sfax (Tunisia), pp. 1-5, March 2014.

[6] H. Patel and V. Agarwal, "Matlab- based Modeling to Study the Effects of Partial Shading on PV Array Characteristic," IEEE Trans. On Energy conversion, vol. 23, no. 1, pp. 302-310, 2008.

[7] M. Davarifar, A. Rabhi, A. Hajjaji and E. Kamal, Z. Daneshifar," Partial Shading Fault Diagnosis in PV System With Discrete Wavelet Transform (DWT) ". 3rd International Conference on Renewable Energy Research and Applications, Milwakuee, USA 19-22, pp. 810-814, Oct 2014.

[8] Wail Rezgui, Leila-Hayet Mouss, Nadia Kinza Mouss, Mohamed Djamel Mouss, Yassine Amirat, Mohamed Benbouzid, "Electrical Faults Modeling of the Photovoltaic Generator", available on line on https://hal.archivesouvertes.fr/hal-01017387.

[9] Wail Rezgui, Leila Hayet Mouss, Mohamed Djamel Mouss, “Modeling of a photovoltaic field in malfunctioning", Control, Decision and Information Technologies (CoDIT), 2013 International Conference on, pp.788-793, 6-8 May 2013.

[10] Long BUN, "Détection et Localisation de Défauts pour un Système PV', PhD thesis Electrical Engineering, University of Grenoble, 2011.

[11] G. M. Masters, Renewable and efficient electric power systems, John Wiley \& Sons, 2013.

[12] Braun, Henry and Banavar, Mahesh and Spanias, Andreas, Signal Processing for Solar Array Monitoring, Fault Detection, and Optimization, Morgan \& Claypool Publishers, 2012. 